\title{
Acute hemodynamic and functional effects of surgical ventricular restoration and heart transplantation in patients with ischemic dilated cardiomyopathy
}

\author{
Maurizio Cotrufo, MD, ${ }^{a}$ Luca Salvatore De Santo, MD, ${ }^{c}$ Alessandro Della Corte, MD, ${ }^{a}$ GianPaolo Romano, MD, \\ Cristiano Amarelli, MD, ${ }^{\mathrm{b}}$ Marisa De Feo, MD, ${ }^{a}$ Giuseppe Santarpino, MD, ${ }^{\mathrm{a}}$ Michelangelo Scardone, MD, ${ }^{\mathrm{a}}$ and \\ Gianantonio Nappi, MD
}

From the Department of Cardiothoracic Sciences, ${ }^{\text {a }}$ Second University of Naples, Naples, Italy; the Department of Cardiovascular Surgery and Transplants, ${ }^{\text {b }}$ Monaldi Hospital, Naples, Italy; and the Department of Cardiac Surgery, ${ }^{\mathrm{c}}$ University of Foggia, Foggia, Italy.

Read at the RESTORE Group Meeting, Philadelphia, Pa, April 29, 2006.

Received for publication May 30, 2007; revisions received Sept 13, 2007; accepted for publication Sept 24, 2007.

Address for reprints: Luca Salvatore De Santo, MD, Viale Colli Aminei 491, 80131, Naples, Italy (E-mail: luca. desanto@ospedalemonaldi.it).

J Thorac Cardiovasc Surg 2008;135:1054 60

$0022-5223 / \$ 34.00$

Copyright $(\subset) 2008$ by The American Association for Thoracic Surgery

doi:10.1016/j.jtcvs.2007.09.041
Objectives: Peak oxygen uptake $\left(\mathrm{VO}_{2}\right)$ and ventilatory efficiency have prognostic implications in the population with congestive heart failure. This study evaluated quality-of-life functional capacity after the 2 treatment strategies of surgical ventricular restoration and transplantation for severe left ventricular dysfunction of ischemic cause.

Methods: The 75-patient study population (between 2004 and 2006) with severe heart failure included 35 patients undergoing surgical ventricular restoration (mean age, $62.6 \pm 8.7$ years), sometimes together with coronary artery bypass grafting or mitral surgery, and 40 cardiac transplant recipients (mean age, $55.6 \pm 7.7$ years). Preoperative and 6-month postoperative function (peak $\mathrm{VO}_{2}$, the anaerobic threshold, and the slope of minute ventilation/carbon dioxide uptake), cardiac catheterization parameters (left and right), and hospital and early outcomes were evaluated.

Results: The 2 groups had comparable baseline functional impairment and experienced similar hospital stay and early outcomes. They also showed similar improvements in left ventricular volume indexes and hemodynamic parameters and sustained significant improvements of median $\mathrm{VO}_{2}$, anaerobic threshold, and minute ventilation/carbon dioxide uptake values.

Conclusions: Both surgical strategies resulted in a significant and comparable improvement of functional capacity at the 6-month evaluation. These early studies must be repeated to determine the long-term benefits of surgical ventricular restoration because maximal $\mathrm{VO}_{2}$ and ventilatory efficiency lose their prognostic survival role after transplantation.

I schemic left ventricular dysfunction continues to represent a major health care problem because it affects approximately two thirds of the patients referred for congestive heart failure. Limitations in organ procurement severely restrict the use of heart transplantation, make listing criteria increasingly selective, and strongly support the development of alternative surgical approaches. Dor's pioneering experience $^{1}$ has established the role of surgical ventricular restoration (SVR) to treat ischemic cardiomyopathy after the nidus of a large myocardial scar causes progressive cardiac dilation of remote muscle from adverse remodeling. SVR improves ventricular performance and functional class, with a gratifying 5-year survival and low rate of rehospitalization for heart failure, ${ }^{2,3}$ but the merits, indications, and long-term efficacy of this strategy remain under intense investigation.

Our prior study compared SVR and transplantation treatment of severe ischemic dilated cardiomyopathy ${ }^{4}$ and showed that ventricular reconstructive surgery provided a significant improvement in cardiac function, allowing for a better quality of life and a lower risk of rehospitalization than transplantation but higher hospital mortality. Absent from that analysis were measurements after cardiopulmonary exercise testing 


\section{Abbreviations and Acronyms \\ CPET $=$ cardiopulmonary exercise testing \\ $\mathrm{EF} \quad=$ ejection fraction \\ NYHA $=$ New York Heart Association \\ SVR = surgical ventricular restoration \\ $\mathrm{V}_{\mathrm{E}} \quad=$ minute ventilation \\ $\mathrm{Vo}_{2} \quad=$ oxygen uptake}

(CPET), which is a noninvasive way of evaluating patients with heart failure and is used consistently in the assessment for cardiac transplantation. Values gleaned from analyzing these test results have been a guide to treatment strategy choices used to determine long-term survival ${ }^{5,6}$ but have not yet been compared with values achieved after SVR for dilated ischemic cardiomyopathy. The goal of evaluating patients with end-stage ischemic cardiomyopathy is to determine how oxygen uptake $\left(\mathrm{VO}_{2}\right)$ during exercise is changed after treatment with either ventricular restoration or heart transplantation at the 6-month postoperative interval.

\section{Materials and Methods Study Design}

This is a single-center prospective study analyzing the experience over 18 months with surgical treatment of ischemic cardiomyopathy. From January 2004 through June 2006, 200 patients were operated on for ischemic cardiomyopathy at the Department of CardioThoracic Sciences, Second University of Naples, "V. Monaldi" Hospital. Inclusion criteria for the present study were end-stage ischemic cardiomyopathy, defined according to Burch and colleagues ${ }^{7}$; end-systolic volume index of $50 \mathrm{~mL} / \mathrm{m}^{2}$ or greater; and an ejection fraction $(\mathrm{EF})$ of $35 \%$ or less, excluding cases of isolated lateral or posterior wall aneurysm. Thus the analysis included $75 \mathrm{pa}-$ tients ( 53 male and 22 female patients) between 41 and 75 years of age (mean age, $60.6 \pm 5.2$ years) divided into 2 groups. Group A included 35 patients (mean age, $62.6 \pm 8.7$ years; 10 female patients) who underwent SVR with endoventricular circular patch plasty associated with coronary artery bypass grafting, mitral surgery, or both. Group B included 40 recipients who underwent orthotopic cardiac transplantation (mean age, $55.6 \pm 7.7$ years; 12 female patients).

\section{Patient-Procedure Matching Criteria}

Choice of surgical treatment was based on morphologic and functional cardiac parameters, but the SVR exclusion criteria, according to Dor, ${ }^{8}$ included (1) severely decreased right ventricular function, (2) lack of ischemic areas suitable for revascularization, and (3) lack of contraction improvement of basal segments during echodobutamine. Conversely, age greater than 65 years was a relative contraindication to heart transplantation because of the shortage of available donor organs and the high likelihood of waiting-time decompensation.

\section{Surgical Procedures}

All the restoration procedures were performed by means of a median sternotomy using mild hypothermic $\left(28^{\circ} \mathrm{C}\right)$ cardiopulmonary bypass, aortic crossclamping, and myocardial protection with intermittent St Thomas I perfusion. The strategy included (1) endoventricular patch plasty according to the principles of Dor's technique with our modifications, (2) repair of the regurgitant mitral valve (28.5\%) with either Alfieri or Bolling techniques, and (3) coronary bypass grafting to provide complete revascularization $(2.1 \pm 0.9$ grafts in 32 patients). Map-guided cryoablation was performed in $8.5 \%$ of patients with preoperative ventricular arrhythmias. Prophylactic intra-aortic balloon counterpulsation was instituted just before induction of anesthesia in $22.8 \%$ of patients with pronounced congestive heart failure to achieve intraoperative hemodynamic stability and prevent low postoperative cardiac output. Outpatient follow-up management included maintenance of an optimal heart failure regimen including $\beta$-blockers and angiotensin-converting enzyme inhibitors, which were administered by our clinic physicians.

During transplantation, the donor heart was procured by using standard techniques and was protected with $2 \mathrm{~L}$ of cold $\left(4^{\circ} \mathrm{C}\right.$ to $8^{\circ} \mathrm{C}$ ) Celsior solution (Genzyme Corporation, Cambridge, MA) and topical saline slush. Excised grafts were then immersed in $1 \mathrm{~L}$ of cold Celsior solution and stored on ice in a closed cardiac storage container for transportation. All recipients underwent standard orthotopic transplantation by using the atrial anastomotic technique. Principles of posttransplantation care and immunosuppressive regimen have been described elsewhere. ${ }^{9}$

\section{Cardiac Rehabilitation Program}

All patients in both groups enrolled in a comprehensive postoperative exercise rehabilitation program based on protocols designed by the European Heart Failure Training Group and the American Heart Association Committee on Exercise, Rehabilitation, and Prevention. ${ }^{10,11}$

\section{CPET and Heart Catheterization}

Patients underwent exercise testing and heart catheterization during the preoperative evaluation and 6 months after the surgical procedure. Endomyocardial biopsy demonstrating the absence of acute rejection was required in patients undergoing heart transplantation before undergoing CPET postoperatively. All patients performed upright bicycle exercise to maximum tolerance with the use of a progressively increasing work rate at 10 to $20 \mathrm{~W} / \mathrm{min}$ after a period of resting and unloaded pedaling, as recommended by Buchfuhrer and associates. ${ }^{12}$ Patients were encouraged to exercise until symptoms were intolerable. Investigator-determined exercise end points were severe ventricular tachycardia of 5 beats or greater, high degree of atrioventricular block, ST-segment depression of $3 \mathrm{~mm}$ or greater, systolic blood pressure of $250 \mathrm{~mm} \mathrm{Hg}$ or greater, or progressive decrease in blood pressure. Breath-by-breath gas exchange measurements were performed with a Cosmed Quark (PFT Ergo, Rome, Italy) metabolic cart. $\mathrm{VO}_{2}$, carbon dioxide output, tidal volume, and breathing rate were measured. Blood gases $\left(\mathrm{PaO}_{2}\right.$ and $\left.\mathrm{PaCO}_{2}\right)$ and $\mathrm{pH}$ were measured at rest and shortly before the end of exercise with the use of arterialized capillary blood samples.

From the above data, minute ventilation $\left(\mathrm{V}_{\mathrm{E}}\right)$, and the ventilatory equivalents for $\mathrm{CO}_{2}$ were calculated. Peak $\mathrm{VO}_{2}$ was determined as the highest $\mathrm{VO}_{2}$ achieved during exercise. The anaerobic threshold $\left(\mathrm{VO}_{2}\right.$ anaerobic threshold) was measured by using the $\mathrm{V}$-slope method. Typical changes in ventilatory equivalents and end-tidal gas concentrations were examined to search for agreement in cases that were questionable with regard to the precise $\mathrm{VO}_{2}$ anaerobic 
threshold values. The $\mathrm{V}_{\mathrm{E}}$ versus $\mathrm{VCO}_{2}$ slope was calculated by means of linear regression, excluding the nonlinear part of the data after the onset of ventilatory compensation for metabolic acidosis. The 6-minute walking distance, a test widely used for its ease of administration and reproducibility, was not performed in the present study. However, the CPET is noninvasive, more discriminating, and above all more useful in comparing different treatment groups in that it is more sensitive in detecting even small differences in exercise capacity. ${ }^{13}$

The most recent right heart catheterization was used to measure preoperative cardiac hemodynamic data: mean pulmonary artery pressure, systolic pulmonary artery pressure, diastolic pulmonary artery pressure, pulmonary capillary wedge pressure, cardiac index, and pulmonary vascular resistance index. The same hemodynamic parameters were obtained from the postoperative Swan-Ganz catheter measurements. Coronary catheterization and left ventriculography were contemporarily performed. Each angiogram was reviewed in detail, independent of the clinical review. The angiograms were reviewed by 2 observers familiar with the spectrum of allograft coronary artery disease to arrive at a consensus regarding the subjective grading of these films; the modified classification proposed by Gao and coworkers ${ }^{14}$ was used. Abnormalities were classified to distinguish involvement of proximal epicardial large vessels and distal small vessels (tertiary branches or greater), as well as the character and extent of luminal encroachment (mild diffuse luminal irregularity, focal stenosis, or diffuse vascular obliteration), as defined by Gao and coworkers. ${ }^{14}$ The finding of focal angiographic stenosis of $70 \%$ or greater or evidence of diffuse large- or small-vessel obliteration defined "severe" disease. The images of left cine ventriculograms were digitized to obtain the left ventricular volume by means of biplane analysis. The left ventricular end-systolic volume index, left ventricular end-diastolic volume index, and EF were calculated.

\section{Follow-up and Statistical Analysis}

All preoperative, hospital, and follow-up data (total follow-up, 1182 months per patient; mean follow-up of group A, $16.9 \pm 6.9$ months; mean follow-up of group B, $17.4 \pm 8.5$ months) were recorded in a dedicated electronic database. Hospital mortality was defined as death before the 30th postoperative day. SPSS software (version 10.1; SPSS, Inc, Chicago, Ill) was used for statistical analysis. Data were expressed as means \pm standard deviations for continuous variables or counts and percentages for categorical variables. Analysis of variance and $\chi^{2}$ Pearson or Fisher exact tests were used for statistical evaluation of the differences between groups. Two-tailed paired $t$ tests were used for intragroup comparisons of hemodynamic and functional data (before treatment vs after treatment). Nonparametric tests were used in case of skewed distribution.

The authors had full access to the data and take responsibility for its integrity. All authors have read and agree to the manuscript as written.

\section{Results}

\section{Preoperative Clinical Characteristics}

Table 1 presents the preoperative clinical and demographic features of the patient population. Those offered orthotopic transplantation were younger because of the age restriction of transplant candidacy and had more prior cardiac operations. Both groups had a similar sex distribution, incidence
TABLE 1. Preoperative demographics and clinical features

\begin{tabular}{lccl}
\hline & $\begin{array}{c}\text { Group A } \\
\text { (35 patient) }\end{array}$ & $\begin{array}{c}\text { Group B } \\
\text { (40 patients) }\end{array}$ & $\begin{array}{c}\boldsymbol{P} \\
\text { value }\end{array}$ \\
\hline Age (y) & $62.6 \pm 8.7$ & $55.6 \pm 7.7$ & .001 \\
Female sex & $10(28.6 \%)$ & $12(30 \%)$ & $\mathrm{NS}$ \\
Diabetes & $13(37.1 \%)$ & $15(37.5 \%)$ & $\mathrm{NS}$ \\
Prior CABG & $10(28.6 \%)$ & $22(55 \%)$ & .013 \\
Preoperative & $3.2 \pm 0.2 ; 29$ & $3.3 \pm 0.18 ; 29$ & $\mathrm{NS}$ \\
NYHA & $(82.8 \%) ; 6$ & $(72.5 \%) ; 11$ & \\
& $(17.2 \%)$ & $(27.5 \%)$ & \\
Preoperative EF (\%) & $27.1 \pm 4.5$ & $25.3 \pm 7.5$ & $\mathrm{NS}$ \\
Presence of MR & $37.1 \%$ & $47.5 \%$ & $\mathrm{NS}$ \\
MR $\geq$ grade 2 & $28.5 \%$ & $42.5 \%$ & $\mathrm{NS}$ \\
Time to operation (mo) & $42.9 \pm 56$ & $40.2 \pm 51.7$ & $\mathrm{NS}$ \\
\hline
\end{tabular}

$N S$, Not significant; $C A B G$, coronary artery bypass grafting; NYHA, New York Heart Association; $E F$, ejection fraction; $M R$, mitral regurgitation.

of diabetes, New York Heart Association (NYHA) class, presence and degree of mitral regurgitation, and comparable mean time interval between diagnosis and surgical intervention.

\section{Postoperative Data and Hospital and Postdischarge Outcomes}

Hospital mortality was not different between the 2 treatments (11.4\% vs $7.5 \%)$. After SVR, mortality was from low cardiac output in 3 patients and multiorgan failure in 1 patient. The 3 posttransplantation deaths were due to acute graft failure in 1 patient, pneumonia in 1 patient, and multiorgan failure in 1 patient. Global systolic function improved postoperatively in survivors in both groups. The EF increased from $28.1 \% \pm$ $7.3 \%$ preoperatively to $34.5 \% \pm 9.3 \%$ postoperatively in group A $(P<.001)$ and from $27.3 \% \pm 6 \%$ to $49.8 \% \pm$ $7 \%$ in group B $(P<.001)$. During follow-up, one sudden death occurred after SVR, and 1 death from acute rejection occurred after transplantation. Two patients in group A and 1 in group B experienced heart failure recurrence. Of these, the patients undergoing SVR and experiencing heart failure recurrence had very severe preoperative ventricular enlargement associated with mitral regurgitation, poor coronary targets for revascularization, or both.

\section{CPET and Cardiac Catheterization Analysis}

Similar symptom improvement occurred in both groups because mean postoperative NYHA class decreased from $3.3 \pm 0.2$ and $3.2 \pm 0.18$ to $1.7 \pm 1.1$ and $1.3 \pm 0.3$, respectively. Left heart catheterization disclosed no evidence of allograft coronary disease in heart transplant recipients. All bypass grafts except 1 were patent in group A. Table 2 summarizes cardiac catheterization data, CPET results, and Weber-Janicki class assessment and medical therapy. In comparison with preoperative status, surgical intervention conferred a significant and homogeneous functional benefit 
TABLE 2. Functional and hemodynamic parameters, medications, and Weber-Janicki class

\begin{tabular}{|c|c|c|c|c|}
\hline & \multicolumn{2}{|c|}{ Group A } & \multicolumn{2}{|c|}{ Group B } \\
\hline & Preoperative & Postoperative & Preoperative & Postoperative \\
\hline LVEDVI $\left(\mathrm{mL} / \mathrm{m}^{2}\right)$ & $113 \pm 63$ & $79 \pm 23^{*}$ & $115 \pm 75$ & $68 \pm 12^{*}$ \\
\hline LVESVI $\left(\mathrm{mL} / \mathrm{m}^{2}\right)$ & $77.4 \pm 41$ & $53 \pm 24^{*}$ & $78.6 \pm 31.2$ & $27 \pm 8^{*}$ \\
\hline $\mathrm{V}_{0_{2}}$ peak $\left(\mathrm{mL} \cdot \mathrm{kg}^{-1} \cdot \mathrm{min}^{-1}\right)$ & $12 \pm 1.3$ & $16 \pm 1.5^{*}$ & $9.5 \pm 3$ & $15.2 \pm 0.8^{*}$ \\
\hline AT $\left(\mathrm{mL} \cdot \mathrm{kg}^{-1} \cdot \mathrm{min}^{-1}\right)$ & $9.1 \pm 0.9$ & $11 \pm 1^{*}$ & $8.4 \pm 0.7$ & $12 \pm 1^{*}$ \\
\hline $\mathrm{V}_{\mathrm{E}} / \mathrm{VcO}_{2}$ slope & $34.8 \pm 8.5$ & $29.2 \pm 9.9^{*}$ & $38.4 \pm 6$ & $31.4 \pm 3.8^{*}$ \\
\hline $\mathrm{Cl}\left(\mathrm{L} \cdot \mathrm{min}^{-1} \cdot \mathrm{m}^{-2}\right)$ & $1.82 \pm 0.88$ & $2.82 \pm 0.47^{*}$ & $1.7 \pm 0.45$ & $2.75 \pm 0.52^{*}$ \\
\hline PVRI (WU/m²) & $4.85 \pm 1.8 \dagger$ & $2.98 \pm 0.68^{*}$ & $5.8 \pm 1.4$ & $2.78 \pm 1.6^{*}$ \\
\hline PAP mean $(\mathrm{mm} \mathrm{Hg})$ & $42 \pm 12.11$ & $26.8 \pm 4^{*}$ & $39 \pm 11$ & $22 \pm 7^{*}$ \\
\hline PCP $(\mathrm{mm} \mathrm{Hg})$ & $16 \pm 4.9 \dagger$ & $14 \pm 6.2^{*}$ & $25 \pm 9$ & $12 \pm 4^{*}$ \\
\hline \multicolumn{5}{|l|}{ Medication } \\
\hline$\beta$-Blockers & $29(82.8 \%) \dagger$ & $25(80.6 \%)$ & $34(85 \%)$ & $4(10.8 \%)^{*}$ \\
\hline ACE inhibitors & $33(94.3 \%)$ & $28(90.3 \%)$ & $39(97.5 \%)$ & $25(67.6 \%)$ \\
\hline Diuretic & $20(57.2 \%)$ & $15(48.3 \%)$ & $32(80 \%)$ & $12(32.4 \%)$ \\
\hline Spironolactone & $20(57.2 \%)$ & $16(51.6 \%)$ & $33(82.5 \%)$ & $2(5.4 \%)$ \\
\hline Digoxin & $23(65.7 \%)$ & $12(38.7 \%)$ & $21(52.5 \%)$ & - \\
\hline Anticoagulants/aspirin & $26(74.4 \%)$ & $31(100 \%)$ & $40(100 \%)$ & $37(100 \%)$ \\
\hline \multicolumn{5}{|l|}{ Weber-Janicki class } \\
\hline A & - & —* & - & — \\
\hline B & $2(5.7 \%)$ & $14(45.2 \%)$ & $1(2.5 \%)$ & $15(40.5 \%)$ \\
\hline C & $26(74.3 \%)$ & $16(51.6 \%)$ & $31(77.5 \%)$ & $20(54 \%)$ \\
\hline $\mathrm{D}$ & $7(20 \%)$ & $1(3.2 \%)$ & $8(20 \%)$ & $2(5.5 \%)$ \\
\hline$E$ & - & - & - & - \\
\hline
\end{tabular}

LVEDVI, Left ventricular end-diastolic volume index; $L V E S V I$, left ventricular end-systolic volume index; $V_{0}$, oxygen uptake; $A T$, anaerobic threshold; $V_{E} / V_{c o}{ }_{2}$, minute ventilation/carbon dioxide uptake; $C l$, cardiac index; $P V R I$, pulmonary vascular resistance index; $P A P$, pulmonary artery pressure; $P C P, P u l m o n a r y ~ c a p-$ illary pressure; $A C E$, angiotensin-converting enzyme. ${ }^{*} P<.05$, preoperative versus postoperative. $\dagger P<.05$, preoperative group $A$ versus group $B$.

in both groups, as shown in Table 2. However, transplant recipients required significantly less cardiovascular therapy but needed an immunosuppressive regimen.

\section{Discussion}

This prospective review, evaluating functional recovery of patients affected by ischemic cardiomyopathy treated either with heart transplantation or left ventricular restoration, showed similar improvement with both methods, thereby implying that absence of donor heart availability does not diminish the performance benefit gained from using the patients' own tissues to surgically reconstitute cardiac size and shape. The most important findings show that both strategies (1) result in similar hospital and early outcomes and (2) confer a comparable functional parameter improvement after measurement by means of cardiopulmonary exercise and clinical assessment. In this perspective it should be noted that although patients undergoing transplantation were considered unsuitable for any other surgical therapy, many of the patients receiving SVR could have been offered heart transplantation based on their preoperative CPET parameters (mean maximal $\mathrm{VO}_{2}, 12 \pm 1.3 \mathrm{~mL} \cdot \mathrm{kg}^{-1} \cdot \mathrm{min}^{-1}$ ). However, the degree of CPET performance observed after SVR might imply a significant prognostic benefit based on prior reports in patients undergoing transplantation. ${ }^{5,6}$

\section{Prognostic Role of CPET in Heart Failure}

The value of CPET after heart failure is the capacity to place a numeric value on the ability to exercise and thereby convey a more realistic measure of efficiency of cardiac output to supply oxygen for body needs than is available from the more subjective NYHA classification. Of equal importance is that CPET is a pivotal modality in the initial evaluation of patients with advanced heart failure ${ }^{15}$ during evaluation for transplantation, yet is infrequently used in heart failure clinics for patients not considered for transplantation. For example, Mancini and associates ${ }^{16}$ found that peak $\mathrm{VO}_{2}$ was the single best predictor of survival in patients considered for cardiac transplantation. Recent studies of ventilatory expired gas parameter show that a high $\mathrm{V}_{\mathrm{E}} / \mathrm{VCO}_{2}$ ratio at peak exercise or a high slope at submaximal exercise provides a powerful independent index of poor prognosis. ${ }^{17}$ Furthermore, the mortality rate of patients with a maximal $\mathrm{Vo}_{2}$ of $14.5 \mathrm{~mL}$. $\mathrm{kg}^{-1} \cdot \min ^{-1}$ or less was twice that of patients whose maximal $\mathrm{VO}_{2}$ exceeded this value in the Veterans Administration Heart Failure Trial, and this functional test exerted a stronger predicting role than the type of drug treatment. ${ }^{18}$

\section{Effects of SVR and Heart Transplantation on Hemodynamic and CPET Performance}

Previous studies have demonstrated that SVR significantly improves EF, left ventricular size, left ventricular shape, 
hemodynamic parameters, and NYHA functional status in patients with congestive heart failure. Studies have also shown that SVR improves mechanical dyssynchrony, levels of neurohormones associated with congestive heart failure, cardiac function in high-risk surgical candidates, and myocardial performance in nonischemic areas remote from scars. ${ }^{1-3,19-21}$ Each of these factors improves tissue oxygen delivery and is the infrastructure of the reported CPET findings, which, to our knowledge, are the first evidence of significant improvements both in CPET and hemodynamic performance after ventricular restoration. The degree of postoperative dimensional and hemodynamic improvement presented in this series is consistent with prior data ${ }^{19,21}$ and is due to the following surgically induced changes: (1) complete revascularization that includes reperfusion of the upper part of the septum; (2) patient-tailored reduction of ventricular volume by means of exclusion of septal, anterior, and inferior components, together with lowering ventricular wall stress and improving remote zone mechanical efficiency; (3) restoration of the physiologically elliptical left ventricular shape to optimize mechanical efficiency while both avoiding incorrect positioning of the papillary muscles and worsening of diastolic dysfunction; and (4) correction of mitral regurgitation, as described by Menicanti and colleagues. ${ }^{22,23}$

Despite improvement in survival and symptoms attributable to transplantation, exercise capacity, as assessed by means of CPET, remains markedly impaired when compared with that of healthy individuals and might not be different from that of medically stabilized patients with heart failure. ${ }^{5,24}$ Hence some cardiac transplant recipients, such as those included in the present work, have disappointing exercise performance that impairs quality of life, despite apparently normal resting cardiac function. Responsible mechanisms that limit normal return of peak exercise capacity in this transplant cohort include parasympathetic and sympathetic cardiac denervation that increases resting heart rate, attenuates heart rate response at peak exercise, and delays normalization of heart rate after exercise. Furthermore, diastolic dysfunction and limited cardiac contractile reserve allow contractile impairment to supplement these chronotropic changes, and these mechanical alterations occur simultaneously with altered peripheral circulatory mechanisms in transplant recipients ${ }^{24}$ and might be worsened in patients with higher NYHA status in ischemic transplant recipients. ${ }^{6,25}$ These data were determined only 6 months after transplantation and without evidence of secondary coronary disease but directly mirror the Registry of the International Society for Heart and Lung Transplantation, ${ }^{26}$ which shows that peak oxygen consumption might lose prognostic significance after transplantation.

\section{Clinical Implications}

The significant functional recovery observed in this study might indicate an improved long-term prognosis after SVR surgery because improved oxygen consumption is associated with lower mortality, as shown by Lund and coworkers, ${ }^{27}$ who studied the prognostic value of peak $\mathrm{VO}_{2}$ in 227 adults with heart failure who were reevaluated more than 60 days after initial evaluation. Patients whose values improved from a high- or medium-risk Heart Failure Survival Score or peak $\mathrm{VO}_{2}$ values $\left(<10 \mathrm{~mL} \cdot \mathrm{kg}^{-1} \cdot \mathrm{min}^{-1}\right.$ and $10-14$ $\mathrm{mL} \cdot \mathrm{kg}^{-1} \cdot \min ^{-1}$, respectively) to lower-risk values $\left(>14 \mathrm{~mL} \cdot \mathrm{kg}^{-1} \cdot \mathrm{min}^{-1}\right)$ had 1 -year event-free survival rates of $89 \%$ and $83 \%$ after $\beta$-blocker therapy alone and were thereby removed from the transplant waiting list. ${ }^{27,28}$ Furthermore, transplantation could be safely deferred in patients whose peak $\mathrm{VO}_{2}$ value was $14 \mathrm{~mL} \cdot \mathrm{kg}^{-1} \cdot \min ^{-1}$ or greater, where their survival exceeded that of patients undergoing heart transplantation. ${ }^{15}$ Notably, the mean posttransplantation peak $\mathrm{VO}_{2}$ value of $16 \pm 1.5 \mathrm{~mL} \cdot \mathrm{kg}^{-1}$. $\min ^{-1}$ was less than the normal value threshold of greater than $18 \mathrm{~mL} \cdot \mathrm{kg}^{-1} \cdot \min ^{-1}$, which seemed to unfavorably compare with the reports of Leung and associates ${ }^{5}$; however, in that study only one third of patients had ischemic causes, and they were remarkably younger (mean age, 48 years) and had higher preoperative functional capacity (preoperative peak $\mathrm{VO}_{2}, 16 \mathrm{~mL} \cdot \mathrm{kg}^{-1} \cdot \mathrm{min}^{-1}$ ) than in the present experience.

In our study mean postoperative peak $\mathrm{VO}_{2}$ in patients undergoing SVR was $16 \pm 1.5 \mathrm{~mL} \cdot \mathrm{kg}^{-1} \cdot \mathrm{min}^{-1}$, thus conferring a lower-risk prognosis to an initially high-risk cohort. Similar better prognosis considerations exist after $\mathrm{V}_{\mathrm{E}} / \mathrm{VCO}_{2}$ slope analysis because the mean postoperative values in this report are lower than the greater than 34 cutoff known to imply a poor prognosis. ${ }^{29}$ The selection of a 6-month interval for the first measurement might provide an early assessment because neuroendocrine changes recover over 1 year, ${ }^{19}$ so that subsequent testing is needed to determine whether there is further improvement. SVR also avoids the aforementioned chronotropic and mechanical changes after transplantation, so that these observations suggest that the mortality of patients with ischemic cardiomyopathy can be significantly reduced by means of restoration surgery; remote muscle function might progressively improve, and the risk of secondary coronary disease after transplantation is avoided. Further testing is also essential to determine whether ventricular redilation is prevented because increased ventricular volume will counteract these positive results.

This study compared CPET results of SVR with those of heart transplantation. Another therapeutic option used for specific subsets of patients with dilated cardiomyopathy is resynchronization, and comparative studies could be performed, using $\mathrm{VO}_{2}$ as an end point. To date, in a randomized study ${ }^{30}$ a slight improvement in peak $\mathrm{Vo}_{2}$ value has been reported, and a recent study has claimed an increase of peak $\mathrm{VO}_{2}$ value from 13 to $14.8 \mathrm{~mL} \cdot \mathrm{kg}^{-1} \cdot \mathrm{min}^{-1}$ at 12 months, ${ }^{31}$ which is lower than our 6-month value, but no comparison with other treatment modalities has been carried out. 


\section{Study Limitations}

This study analyzed the effect of SVR surgery on CPET performance in a small number of patients. Importantly, the improvement of left ventricular function in the patients studied is in close agreement with previous reports from our institution $^{4}$ and from larger series, ${ }^{1-3,20-23}$ indicating that the patients enrolled in this study are indeed representative. SVR represents a surgical strategy aimed to correct all the anatomic and functional determinants of heart failure in ischemic cardiomyopathy. In doing so, our efforts are directed toward the vessel, valve, and ventricle, so that evaluation of the relative merits of each single operative step on functional and hemodynamic results is hampered, especially because continued medical therapy and the comprehensive rehabilitation program might have contributed to the improvement. The limited study sample prevented us from stratifying patients according to preoperative features (ie, mitral regurgitation, larger ventricles, and viability of remote areas), and the short 6-month follow-up analysis prevents any speculation on left ventricular redilatation late after surgical intervention, even though the stability of SVR results is supported by the studies of Dor and colleagues. ${ }^{32} \mathrm{~A}$ longer follow-up (at least 1 year) is also needed to investigate the effects of late neuroendocrine rearrangements after ventricular volume change.

\section{Conclusions}

SVR is a comprehensive surgical approach tailored to address all pathophysiologic ventricular geometric factors contributing to heart failure development in ischemic patients, and application of this procedure provided a cohort of hospital survivors displaying the same significant CPET performance and hemodynamic improvement observed in a cohort of patients undergoing transplantation. These results support the hypothesis that direct improvement of cardiovascular function and optimization of ventricular geometry might improve functional capacity by acting on the intracardiac determinants of cardiac dysfunction, together with simultaneous correction of vessel and valve factors. Further studies are required to determine the durability of functional improvement because this favorable response after SVR might imply a long-term survival benefit that is associated with a better quality of life than currently available with either conventional treatments or after the use of cardiac transplantation, which has a limited number of available donor organs.

\section{References}

1. Dor V, Sabatier M, Di Donato M, Montiglio F, Toso A, Maioli M. Efficacy of endoventricular patch plasty in large postinfarction akinetic scar and severe left ventricular dysfunction: comparison with a series of large dyskinetic scars. J Thorac Cardiovasc Surg. 1998; 116:50-9.

2. Athanasuleas CL, Buckberg GD, Stanley AW, Siler W, Dor V, Di Donato M, et al. Surgical ventricular restoration in the treatment of congestive heart failure due to post-infarction ventricular dilation. J Am Coll Cardiol. 2004;44:1439-45.
3. Athanasuleas CL, Buckberg GD, Stanley AW, Siler W, Dor V, Di Donato $\mathrm{M}$, et al. Surgical ventricular restoration: the RESTORE Group experience. Heart Fail Rev. 2004;9:287-97.

4. Cotrufo M, Romano GP, De Santo LS, Della Corte A, Amarelli C, Cafarella G, et al. Treatment of extensive ischemic cardiomyopathy: quality of life following two different surgical strategies. Eur J Cardiothorac Surg. 2005;27:481-7.

5. Leung TC, Ballman KV, Allison TG, Wagner JA, Olson LJ, Frantz RP, et al. Clinical predictors of exercise capacity 1 year after cardiac transplantation. J Heart Lung Transplant. 2003;22:16-27.

6. Martinelli L, Rinaldi L, Pederzoli C, Goggi C, Mantovani V, Gavazzi A, et al. Different results of cardiac transplantation in patients with ischaemic and dilated cardiomyopathy. Eur J Cardiothorac Surg. 1995;9: 644-50.

7. Burch GE, Tsui CY, Harb JM. Ischemic cardiomyopathy. Am Heart J. 1972;83:340-50.

8. Dor V. The endoventricular circular patch plasty ("Dor procedure") in ischemic akinetic dilated ventricles. Heart Fail Rev. 2001;6:187-93.

9. De Santo LS, Amarelli C, Romano G, Della Corte A, Torella M, Mastroianni C, et al. Evolving practice patterns in heart transplantation: a single-center experience over 15 years. Transplant Proc. 2004;36: 627-30.

10. European Heart Failure Training Group. Experience from controlled trials of physical training in chronic heart failure. Protocol and patient factors in effectiveness in the improvement in exercise tolerance. Eur Heart J. 1998;19:466-75.

11. Pina IL, Apstein CS, Balady GJ, Belardinelli R, Chaitman BR, Duscha BD, et al. Exercise and heart failure: a statement from the American Heart Association Committee on exercise, rehabilitation, and prevention. Circulation. 2003;107:1210-25.

12. Buchfuhrer MJ, Hansen JE, Robinson TE. Optimizing the exercise protocol for cardiopulmonary assessment. J Appl Physiol. 1983;55: 1558-64.

13. Oudiz RJ, Barst RJ, Hansen JE, Sun XG, Garofano R, Wu X, et al. Cardiopulmonary exercise testing and six-minute walk correlations in pulmonary arterial hypertension. Am J Cardiol. 2006;97:123-6.

14. Gao SZ, Alderman EL, Schroeder JS, Silverman JE, Hunt SA. Accelerated coronary vascular disease in the heart transplant patient: coronary arteriographic findings. JAMA. 1988;12:334-40.

15. Milani RV, Lavie CJ, Mehra MR. Cardiopulmonary exercise testing: how do we differentiate the cause of dyspnea? Circulation. 2004;110:e27-31.

16. Mancini DM, Eisen H, Kussmaul W, Mull R, Edmunds LH Jr, Wilson JR. Value of peak exercise oxygen consumption for optimal timing of cardiac transplantation in ambulatory patients with heart failure. Circulation. 1991;83:778-86.

17. Corrà U, Mezzani A, Bosimini E, Giannuzzi P. Cardiopulmonary exercise testing and prognosis in chronic heart failure. Chest. 2004;126: 942-50.

18. Cohn JN, Johnson G, Ziesche S, Cobb F, Francis G, Tristani F, et al. A comparison of enalapril with hydralazine-isosorbide dinitrate in the treatment of chronic congestive heart failure. N Engl J Med. 1991; 325:303-10

19. Schenk S, McCarthy PM, Starling RC, Hoercher KJ, Hail MD, Ootaki Y, et al. Neurohormonal response to left ventricular reconstruction surgery in ischemic cardiomyopathy. $J$ Thorac Cardiovasc Surg. 2004; 128:38-43.

20. Tulner SAF, Bax JJ, Bleeker GB, Steendijk P, Klautz RJM, Holman EM, et al. Beneficial hemodynamic and clinical effects of surgical ventricular restoration in patients with ischemic dilated cardiomyopathy. Ann Thorac Surg. 2006;82:1721-8.

21. Versteegh MIM, Lamb HJ, Bax JJ, Curiel FB, van der Wall EE, de Roos A, et al. MRI evaluation of left ventricular function in anterior LV aneurysms before and after surgical resection. Eur J Cardiothorac Surg. 2003;23:609-13.

22. Menicanti L, Di Donato M. Surgical left ventricle reconstruction, pathophysiologic insights, results and expectation from the STICH trial. Eur J Cardiothorac Surg. 2004;26(suppl):S42-7.

23. Menicanti L, Di Donato M, Castelvecchio S, Santambrogio C, Montericcio V, Frigiola A, et al. Functional ischemic mitral regurgitation in anterior ventricular remodeling: results of surgical ventricular restoration with and without mitral repair. Heart Fail Rev. 2004;9:317-27. 
24. Nanas SN, Terrovitis JV, Charitos C, Papazachou O, Margari Z, Tsagalou EP, et al. Ventilatory response to exercise and kinetics of oxygen recovery are similar in cardiac transplant recipients and patients with mild chronic heart failure. J Heart Lung Transplant. 2004;23:1154-9.

25. Cope JT, Kaza AK, Reade CC, Shockey KS, Kern JA, Tribble CG, et al. A cost comparison of heart transplantation versus alternative operations for cardiomyopathy. Ann Thorac Surg. 2001;72:1298-305.

26. Taylor DO, Edwards LB, Mohacsi PJ, Boucek MM, Trulock EP, Keck BM, et al. The Registry Of The International Society for Heart and Lung Transplantation: Twentieth Official Adult Heart Transplant Report-2003. J Heart Lung Transplant. 2003;22:616-24.

27. Lund LH, Aaronson KD, Mancini DM. Validation of peak exercise oxygen consumption and the heart failure survival score for serial risk stratification in advanced heart failure. Am J Cardiol. 2005;95:734-41.

28. Stevenson L, Steimle A, Fonarow G, Kermani M, Kermani D, Hamilton MA, et al. Improvement in exercise capacity of candidates awaiting heart transplantation. J Am Coll Cardiol. 1995;25:163-70.
29. Gitt AK, Wasserman K, Kilkowski C, Kleemann T, Kilkowski A, Bangert $\mathrm{M}$, et al. Exercise anaerobic threshold and ventilatory efficiency identify heart failure patients for high risk of early death. Circulation. 2002;106:3079-84.

30. Young JB, Abraham WT, Smith AL, Leon AR, Lieberman R, Wilkoff B, et al. Combined cardiac resynchronization and implantable cardioversion defibrillation in advanced chronic heart failure: the MIRACLE ICD Trial. JAMA. 2003;289:2685-94.

31. Seifert M, Schlegl M, Hoersch W, Fleck E, Doelger A, Stockburger M, et al. Functional capacity and changes in the neurohormonal and cytokine status after long-term CRT in heart failure patients. Int $J$ Cardiol. 2007;121:68-73.

32. Dor V, DiDonato M, Sabatier M, Montiglio F, Civaia F, RESTORE Group. Left ventricular reconstruction by endoventricular patch plasty repair: a 17-year experience. Semin Thorac Cardiovasc Surg. 2001; 13:435-47. 